\title{
Structural and magnetic studies on copper succinate dihydrate single crystals
}

\author{
M P BINITHA ${ }^{1, *}$ and P P PRADYUMNAN ${ }^{2}$ \\ ${ }^{1}$ Department of Physics, Govt. Arts \& Science College, Kozhikode 673018, India \\ ${ }^{2}$ University of Calicut, Calicut University, P.O. 673635 Malappuram, India \\ *Author for correspondence (binithamp@gmail.com)
}

MS received 21 June 2016; accepted 10 January 2017; published online 21 August 2017

\begin{abstract}
Single crystals of copper succinate dihydrate were grown in silica gel by slow diffusion of copper chloride to sodium metasilicate gel impregnated with succinic acid. The grown crystal was subjected to single crystal X-ray diffraction studies. In its structure each copper atom is penta co-ordinated to oxygen atoms of four succinate oxygens and oxygen of co-ordinated water molecule. The four bis-bidendate succinate anions form syn-syn bridges among two copper atoms to form a polymeric two-dimensional chain. From room temperature vibrating sample magnetometer (VSM) studies, the magnetic moment of the material is calculated as 1.35 Bohr magneton (BM), indicating anti-ferromagnetic interaction between copper atoms and can be explained as due to the orbital overlap of the bridging ligand and the two copper atoms in syn-syn orientation. A strong bonding of the magnetic orbital of equatorially oriented $\mathrm{Cu}$ atom on both sides of the exchange pathway $(\mathrm{Cu}-\mathrm{O}-\mathrm{C}-\mathrm{O}-\mathrm{Cu})$ leads to the anti-ferromagnetic interaction.
\end{abstract}

Keywords. Copper succinate dihydrate; single crystal growth; X-ray diffraction; magnetic moment.

\section{Introduction}

The design and the development of new metal-organic frameworks (MOFs) is one of the main focuses of crystal engineering since such material possess a broad variety of physical properties, functions and applications such as materials chemistry, heterogeneous catalysis, gas storage, polymer magnets, etc. [1-4]. A larger variety of inorganic and organic components can be used to construct MOFs. Supramolecular organized molecular magnets can be constructed by combining both molecule-based magnetism and supramolecular chemistry $[5,6]$. Succinate ligand can serve as a versatile ligand to provide several possibilities for creating supramolecular architectures yielding one-, two- and three-dimensional polymeric networks [7-9]. Hydrogen bonding and bridging among metal atoms via carboxylate groups in these systems gives the necessary support for forming such networks. MOFs of copper complexes have attracted special interest due to their magnetic super exchange interactions among copper atoms through bridging ligands [10,11]. Hydrothermal reaction conditions are generally employed for the synthesis of such frameworks. To make an environmentally friendly growth process, we have employed a simple room temperature gel growth technique for the crystallization of copper succinate dihydrate.

\section{Experimental}

Crystallization of copper succinate was carried out by ionic diffusion in hydro-silica gel. The gelating medium was prepared by titrating aqueous solution of sodium meta silicate of specific gravity 1.04 against $0.5 \mathrm{M}$ succinic acid. Acidic strength and volume were adjusted to maintain the $\mathrm{pH}$ at 5 . This solution was then introduced into standard test tube and after proper gel setting the supernatant copper chloride solution of molarity $0.5 \mathrm{M}$ was poured over it without tampering the meniscus of the gel. Thin plate-like blue crystals of copper succinate were taken out of the gel solution after a month. The growth details, spectroscopic, thermal and dielectric characterization of the crystal were discussed earlier by the authors [12].

After harvesting the grown copper succinate crystals, structural characterization was performed using the single crystal X-ray diffraction technique. The single crystal X-ray diffraction (XRD) data were collected using a Bruker Kappa Apex II diffractometer, with graphitemonochromator Mo-K $\alpha(\lambda=0.71073 \AA)$ radiation. The unit cell dimensions were recorded at $296 \mathrm{~K}$. The magnetic characterization of copper succinate crystals was carried out using a Lakeshore 7404 model vibrating sample magnetometer.

\section{Results and discussion}

\subsection{Structural studies}

A good single crystal of size $0.35 \times 0.30 \times 0.25 \mathrm{~mm}^{3}$ was chosen for the single crystal XRD analysis. The programme SAINT/XPREP was used for data reduction and 
Table 1. Crystal data and structure refinement parameters for copper succinate.

\begin{tabular}{ll}
\hline Parameter & \multicolumn{1}{c}{ Copper succinate } \\
\hline Empirical formula & $\mathrm{C}_{4} \mathrm{H}_{8} \mathrm{Cu} \mathrm{O}_{6}$ \\
Formula weight & 215.65 \\
Temperature & $296(2) \mathrm{K}$ \\
Wavelength & $0.71073 \AA$ \\
Crystal system, & Triclinic, $\mathrm{P}(-1)$ \\
$\quad$ space group & $a=6.4311(4) \AA, \alpha=76.176(2)^{\circ}$ \\
Unit cell & \\
dimensions & $b=7.6129(4) \AA, \beta=73.472(2)^{\circ}$ \\
& $c=8.0730(5) \AA, \gamma=81.559(2)^{\circ}$ \\
Volume & $366.62(4) \AA^{3}$ \\
$Z$ & 2 \\
Calculated density & $1.9535 \mathrm{Mg} \mathrm{m}^{-3}$ \\
Theta range for & 2.77 to $28.24^{\circ}$ \\
$\quad$ data collection & \\
Reflections & $2865 / 1769[R(\mathrm{int})=0.0142]$ \\
$\quad$ collected/unique & \\
Data/restraints/ & $1769 / 6 / 116$ \\
parameters & \\
Goodness-of-fit on & 1.114 \\
$F^{2}$ & \\
Final $R$ indices & $R 1=0.0275, w R 2=0.0848$ \\
{$[I>2$ sigma(I) } & \\
\hline
\end{tabular}

Table 2. Atomic co-ordinates $\left(\times 10^{4}\right)$ and equivalent isotropic displacement parameters $\left(\AA^{2} \times 10^{3}\right)$ of the non-hydrogen atoms. $U$ (eq) is defined as one-third of the trace of the orthogonalized $U \mathrm{ij}$ tensor.

\begin{tabular}{lcccc}
\hline Atom & $x$ & $y$ & $z$ & $U(\mathrm{eq})$ \\
\hline $\mathrm{Cu}(1)$ & $9211(1)$ & $6551(1)$ & $438(1)$ & $18(1)$ \\
$\mathrm{O}(4)$ & $10946(3)$ & $5822(2)$ & $2177(2)$ & $28(1)$ \\
$\mathrm{O}(6)$ & $7814(3)$ & $6885(2)$ & $1499(2)$ & $30(1)$ \\
$\mathrm{O}(1)$ & $6934(3)$ & $5032(2)$ & $2019(2)$ & $28(1)$ \\
$\mathrm{O}(5)$ & $11738(3)$ & $7649(2)$ & $1326(2)$ & $27(1)$ \\
$\mathrm{O}(3)$ & $7465(3)$ & $8865(3)$ & $1368(3)$ & $43(1)$ \\
$\mathrm{O}(1 \mathrm{~S})$ & $2960(4)$ & $1110(3)$ & $2539(4)$ & $49(1)$ \\
$\mathrm{C}(3)$ & $2962(4)$ & $3756(3)$ & $3989(3)$ & $25(1)$ \\
$\mathrm{C}(2)$ & $5041(3)$ & $2484(3)$ & $3674(3)$ & $22(1)$ \\
$\mathrm{C}(1)$ & $6868(3)$ & $3361(3)$ & $2220(3)$ & $20(1)$ \\
$\mathrm{C}(4)$ & $1982(3)$ & $4266(3)$ & $2428(3)$ & $21(1)$ \\
\hline
\end{tabular}

APEX2/SAINT for cell refinement. The structure was solved using SIR92 and refinement was carried out by full-matrix least squares on F2 using SHELXL-97. Based on 2865 reflections and 116 parameters, the residuals converged to $R$ (int) $=$ 0.0142 .

Single crystal XRD studies reveal the triclinic structure for copper succinate dihydrate and the measured cell parameters are $a=6.4311$ (4) $\AA, b=7.6129(4) \AA, c=8.0730(5) \AA$, $\alpha=76.176(2)^{\circ}, \beta=73.472(2)^{\circ}, \gamma=81.559(2)^{\circ}$. Table 1
Table 3. Selected bond lengths (A) for copper succinate.

\begin{tabular}{ll}
\hline $\mathrm{Cu}(1)-\mathrm{O}(1)$ & $1.9591(17)$ \\
$\mathrm{Cu}(1)-\mathrm{O}(4)$ & $1.9646(17)$ \\
$\mathrm{Cu}(1)-\mathrm{O}(6)$ & $1.9648(17)$ \\
$\mathrm{Cu}(1)-\mathrm{O}(5)$ & $1.9698(17)$ \\
$\mathrm{Cu}(1)-\mathrm{O}(3)$ & $2.1211(18)$ \\
$\mathrm{Cu}(1)-\mathrm{Cu}(1) \# 1$ & $2.6062(5)$ \\
$\mathrm{O}(4)-\mathrm{C}(4) \# 2$ & $1.272(3)$ \\
$\mathrm{O}(1)-\mathrm{C}(1)$ & $1.249(3)$ \\
$\mathrm{O}(5)-\mathrm{C}(1) \# 1$ & $1.269(3)$ \\
$\mathrm{C}(3)-\mathrm{C}(4)$ & $1.510(3)$ \\
$\mathrm{C}(3)-\mathrm{C}(2)$ & $1.527(3)$ \\
$\mathrm{C}(2)-\mathrm{C}(1)$ & $1.508(3)$ \\
$\mathrm{C}(1)-\mathrm{O}(5) \# 1$ & $1.269(3)$ \\
$\mathrm{C}(4)-\mathrm{O}(6) \# 3$ & $1.254(3)$ \\
$\mathrm{C}(4)-\mathrm{O}(4) \# 4$ & $1.272(3)$ \\
\hline
\end{tabular}

Table 4. Selected bond angles (deg) for copper succinate. Symmetry transformations used to generate equivalent atoms: $\# 1(-x+2,-y+1,-z), \# 2(x+1, y, z), \# 3(-x+1,-y+1,-z)$, $\# 4(x-1, y, z)$.

$\begin{array}{ll}\mathrm{O}(1)-\mathrm{Cu}(1)-\mathrm{O}(4) & 90.11(8) \\ \mathrm{O}(1)-\mathrm{Cu}(1)-\mathrm{O}(6) & 90.63(8) \\ \mathrm{O}(4)-\mathrm{Cu}(1)-\mathrm{O}(6) & 168.80(7) \\ \mathrm{O}(1)-\mathrm{Cu}(1)-\mathrm{O}(5) & 168.91(7) \\ \mathrm{O}(4)-\mathrm{Cu}(1)-\mathrm{O}(5) & 89.68(8) \\ \mathrm{O}(6)-\mathrm{Cu}(1)-\mathrm{O}(5) & 87.45(8) \\ \mathrm{O}(1)-\mathrm{Cu}(1)-\mathrm{O}(3) & 90.18(8) \\ \mathrm{O}(4)-\mathrm{Cu}(1)-\mathrm{O}(3) & 97.08(9) \\ \mathrm{O}(6)-\mathrm{Cu}(1)-\mathrm{O}(3) & 94.09(9) \\ \mathrm{O}(5)-\mathrm{Cu}(1)-\mathrm{O}(3) & 100.85(8) \\ \mathrm{C}(4) \# 2-\mathrm{O}(4)-\mathrm{Cu}(1) & 122.52(15) \\ \mathrm{C}(4) \# 3-\mathrm{O}(6)-\mathrm{Cu}(1) & 123.71(15) \\ \mathrm{C}(1)-\mathrm{O}(1)-\mathrm{Cu}(1) & 127.97(15) \\ \mathrm{C}(1) \# 1-\mathrm{O}(5)-\mathrm{Cu}(1) & 118.43(14) \\ \mathrm{C}(4)-\mathrm{C}(3)-\mathrm{C}(2) & 112.92(17) \\ \mathrm{C}(1)-\mathrm{C}(2)-\mathrm{C}(3) & 112.65(18) \\ \mathrm{O}(1)-\mathrm{C}(1)-\mathrm{O}(5) \# 1 & 124.6(2) \\ \mathrm{O}(1)-\mathrm{C}(1)-\mathrm{C}(2) & 117.25(19) \\ \mathrm{O}(5) \# 1-\mathrm{C}(1)-\mathrm{C}(2) & 118.16(19) \\ \mathrm{O}(6) \# 3-\mathrm{C}(4)-\mathrm{O}(4) \# 4 & 124.3(2) \\ \mathrm{O}(6) \# 3-\mathrm{C}(4)-\mathrm{C}(3) & 118.1(2) \\ \mathrm{O}(4) \# 4-\mathrm{C}(4)-\mathrm{C}(3) & 117.55(19) \\ \end{array}$

gives the details of the crystal and structure refinement data. The atomic co-ordinates and equivalent thermal parameters for all the non-hydrogen atoms are given in table 2 . Tables 3 and 4 give the selected bond lengths and bond angles.

Figure 1 represents a molecular drawing of the crystal with the atom numbering and figure 2 depicts the packing of the molecules down $b$-axis.

In the structure each copper (II) ion exhibits a $\mathrm{CuO}_{5}$ coordination environment with four oxygen atoms from four 
different succinate groups in the basal position and the coordination geometry is a distorted square-pyramidal.

The corresponding bond lengths are $\mathrm{Cu}-\mathrm{O}_{1}=1.9591(17)$ $\AA, \mathrm{Cu}-\mathrm{O}_{4}=1.9646(17) \AA, \mathrm{Cu}-\mathrm{O}_{5}=1.9698(17) \AA$, $\mathrm{Cu}-\mathrm{O}_{6}=1.9648(17) \AA$. The oxygen atom of water remain in the apical position with a bond length $\mathrm{Cu}-\mathrm{O}_{3}=2.1211$ (18) $\AA$. The copper (II) atom is shifted to a distance of 0.189 (4) $\AA$ from the mean plane formed by the succinate oxygen atoms towards the apical oxygen atom.

The succinate group acts as a bidentate ligand towards each copper (II) ion. The four bis-bidendate succinate anions form syn-syn bridges among two copper atom groups to form a polymeric two-dimensional chain with an intra-molecular

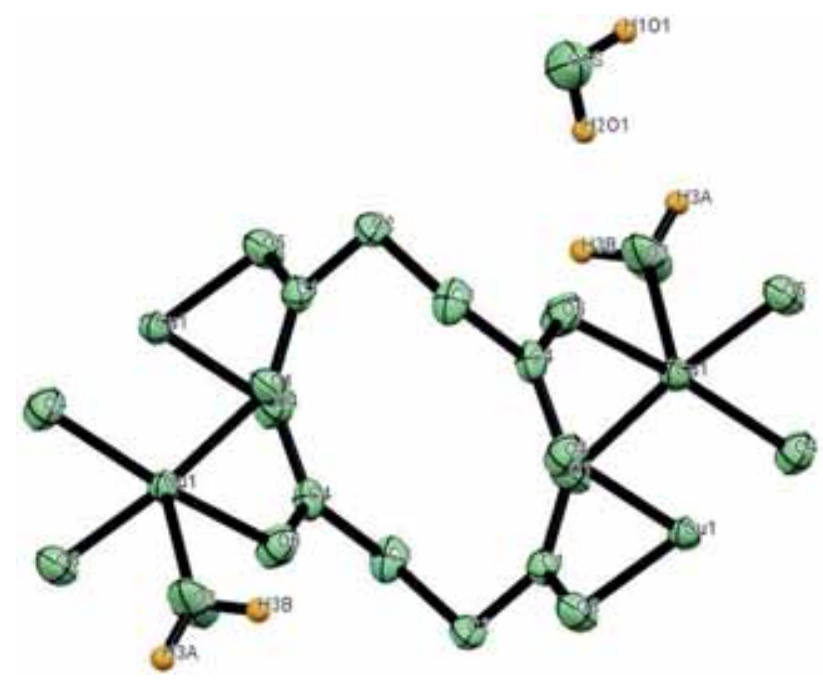

Figure 1. ORTEP of the molecule at $50 \%$ probability.
$\mathrm{Cu}-\mathrm{Cu}$ distance of 2.6062 (5) $\AA$. The two carboxylate planes are almost perpendicular to each other with a dihedral angle of $81.4^{\circ}$

In each asymmetric unit there are two water molecules; one co-ordinated and the other lattice water. This lattice water molecule serves as receptors or donors of the $\mathrm{O} \mathrm{H} \cdots \mathrm{O}$ hydrogen bond and is hydrogen bonded to oxygen of the co-ordinated water molecule $(\mathrm{O} 3)$ and carboxylate oxygen of the succinate group (O4). The co-ordinated water molecule (O3) acts as the donor and gets hydrogen bonded to $\mathrm{O}(3)$ and another carboxylate oxygen $\mathrm{O}(5)$. Thus, these two water molecules in the structure of copper succinate are involved in the extensive network of hydrogen bonds among themselves and are responsible for the stability of the structure. The parameters of hydrogen bonding are depicted in table 5 .

\subsection{Magnetic studies of copper succinate}

The variation of the magnetic moment of copper succinate dihydrate with an external field is depicted in figure 3. The observed hysteresis curve with changing field strength is due to the ferromagnetic or anti-ferromagnetic behaviour of the crystal. The initial increase in the susceptibility may be attributed to relatively faster alignment of dipoles in the beginning. The saturation magnetization of the material is found as $0.00925 \mathrm{emu} \mathrm{g}^{-1}$, the retentivity is $1.2997 \times 10^{-3} \mathrm{emu} \mathrm{g}^{-1}$ and coercivity is $141.13 \mathrm{G}$. The magnetic moment of hydrated copper succinate is calculated as $1.35 \mathrm{BM}$ at room temperature, which is less than the spin-only value of $1.73 \mathrm{BM}$ for one unpaired electron ( $\mathrm{d}^{9}$ system). This value is similar to the values reported earlier for anti-ferromagnetic di-nuclear

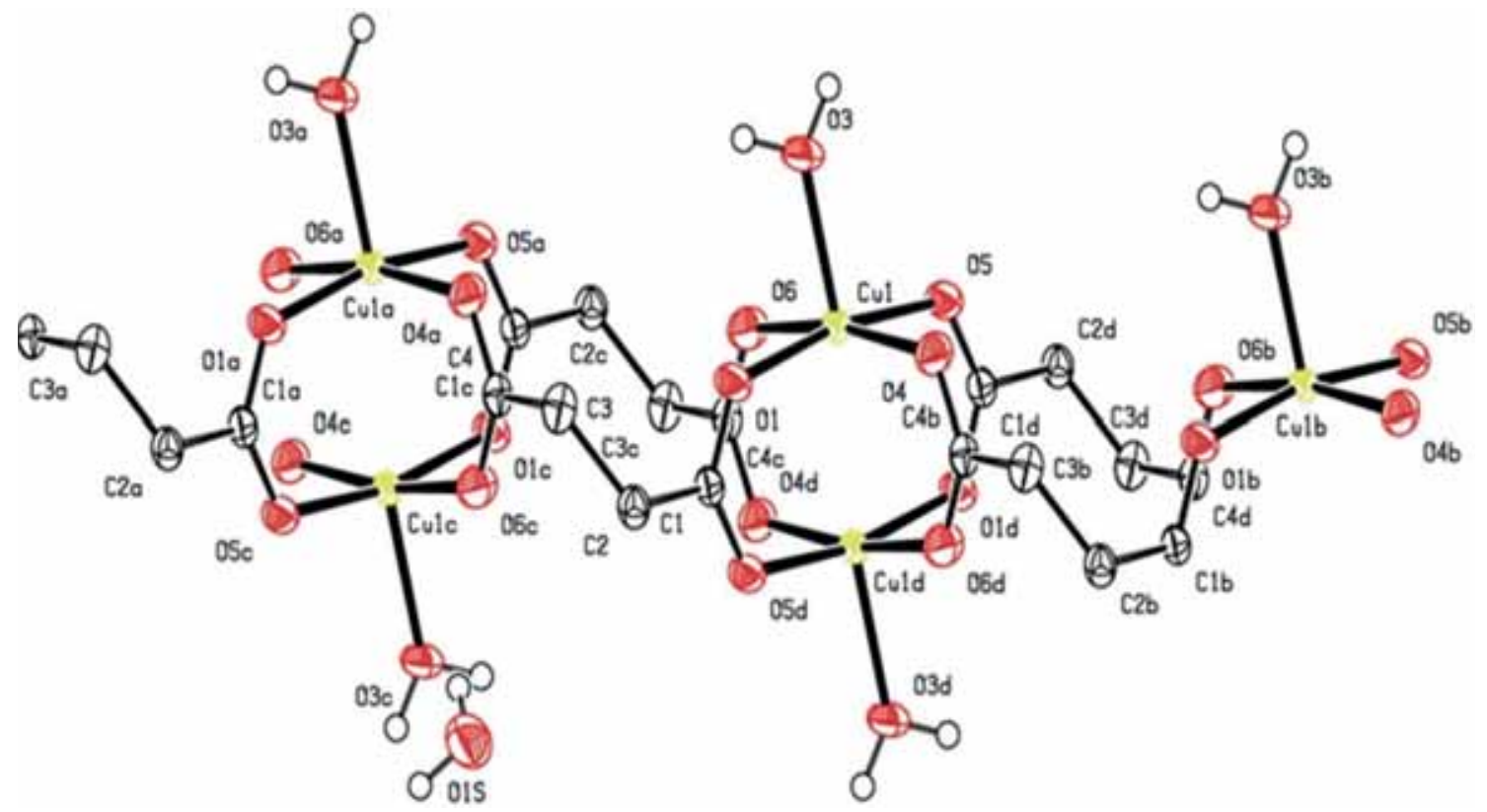

Figure 2. The packing of the molecules down $b$-axis. 
Table 5. Geometries of the H-bonds in copper succinate. Symmetry transformations used to generate equivalent atoms: $\# 1[x-1, y-1, z], \# 2[x, y+1, z], \# 3[-x+2$, $-y+2,-z] ; \mathrm{D}=$ donor, $\mathrm{A}=$ acceptor.

\begin{tabular}{lcccc}
\hline D-H....A & $\mathrm{d}(\mathrm{D}-\mathrm{H}) \AA$ & $\mathrm{d}(\mathrm{H}-\mathrm{A}) \AA$ & $\mathrm{d}(\mathrm{D} . . \mathrm{A}) \AA$ & $<(\mathrm{D}-\mathrm{H} \ldots . . \mathrm{A})^{\circ}$ \\
\hline $\mathrm{O}(1 \mathrm{~S})-\mathrm{H}(1 \mathrm{O} 1) \ldots . \mathrm{O}(4) \# 1$ & 0.853 & 2.108 & 2.94 & 165.27 \\
$\mathrm{O}(3)-\mathrm{H}(3 \mathrm{~B}) \ldots . \mathrm{O}(1 \mathrm{~S}) \# 2$ & 0.833 & 1.965 & 2.779 & 165.33 \\
$\mathrm{O}(3)-\mathrm{H}(3 \mathrm{~A}) \ldots . \mathrm{O}(5) \# 3$ & 0.851 & 1.918 & 2.767 & 175.49 \\
\hline
\end{tabular}

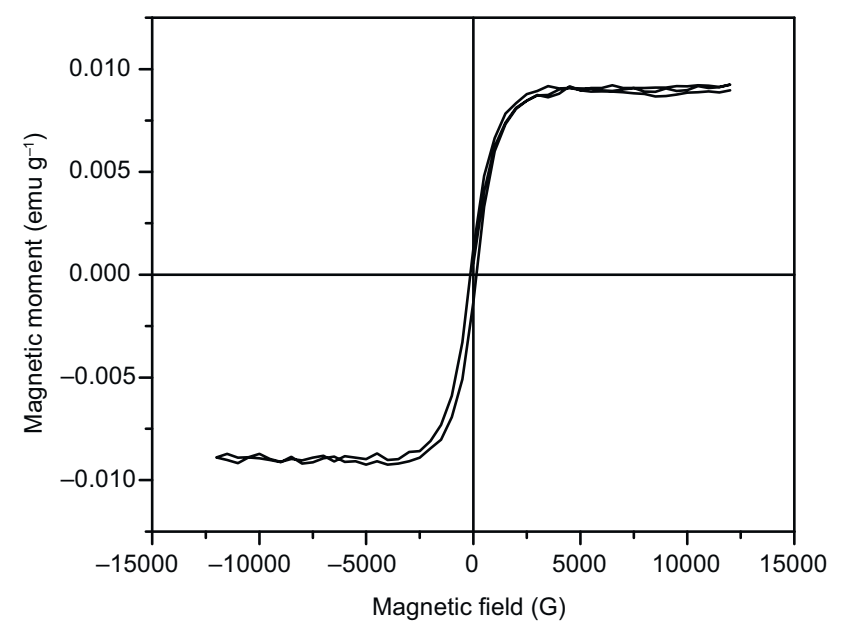

Figure 3. Variation of magnetic moment with the applied field.

or poly-nuclear complexes, where the carboxylate group acts as a bridge among two metal ions in syn-syn confirmation [13].

Super exchange interaction occurs when two magnetic ions are separated by a non-magnetic ion and hence direct exchange is not possible by overlapping of d-electron wavefunction. Thus an exchange interaction mediated by a nonmagnetic ion leads to super exchange interaction. Hybridization of $2 p$ orbital electrons with d orbital at either side causes a minimum energy configuration of the spin arrangement. If the orbital overlaps, the interaction will be negative and the material becomes anti-ferromagnetic and with no overlap the interaction will be positive and ferromagnetic behaviour is exhibited by the material [14].

Each $\mathrm{Cu}$ centre is in $\mathrm{d}^{9}$ electronic configuration and therefore has one unpaired electron each. Direct exchange among the orbitals of these two $\mathrm{Cu}$ atoms is not possible in the above complex since the orbitals are too far apart (2.6062 $\mathrm{A})$. Two spins $S=1 / 2$ of two adjacent copper (II) ions are coupled via the succinate ligand, which can result in either a ferromagnetic or an anti-ferromagnetic behaviour. In the present case, the anti-ferromagnetism of copper succinate dihydrate can be described by an orbital overlap of the bridging ligand and the two copper ions in syn-syn confirmation. The anti-ferromagnetic exchange pathway can be explained in terms of the super-exchange mechanism through the ligand bridge.
From the single crystal X-ray data it is known that in the square pyramidal co-ordination sphere, the equatorially co-ordinated oxygen atoms are closer than the axially coordinated oxygen atom of the water molecule. Hence, the equatorially oriented $\mathrm{Cu}$ orbital is the magnetic, whereas the axially oriented one is not. A strong bonding of the magnetic orbital of equatorially oriented $\mathrm{Cu}$ atom on both sides of the exchange pathway $(\mathrm{Cu}-\mathrm{O}-\mathrm{C}-\mathrm{O}-\mathrm{Cu})$ leads to the antiferromagnetic interaction $[15,16]$.

\section{Conclusions}

The growth of copper succinate dihydrate crystal was accomplished using the silica gel technique, by the controlled reaction of copper chloride with succinic acid. The material crystallizes in triclinic structure with space group $\mathrm{P}(-1)$. Single crystal XRD studies show that in the structure of copper succinate each copper ion exhibits a $\mathrm{CuO}_{5}$ co-ordination environment with four oxygen atoms of four succinate groups in the basal position and oxygen atom of water in the apical position with distorted square-pyramidal co-ordination geometry. The four bis-bidendate succinate anions form synsyn bridges among two copper atoms to form a polymeric two-dimensional chain with an intramolecular $\mathrm{Cu}-\mathrm{Cu}$ distance of $2.606 \AA$. The magnetic properties of the material are studied using the VSM method and the material is found to exhibit anti-ferromagnetic interaction among copper atoms. The exchange interaction among the copper (II) ions propagated through the succinate bridge is strongly dependent on the geometry around the copper ions and the bridging mode of the succinate group.

\section{Acknowledgements}

We would like to acknowledge UGC-SAP and FIST 2 (DST, Govt. of India), for the research facilities in the Department of Physics, University of Calicut. Dr P P Pradyumnan acknowledges DST-SERB for providing financial assistance to undertake this major research project.

\section{References}

[1] Li HuiJun, Zhang ErPeng, Guo QianQian, Hou HongWei and Fan YaoTing 2010 Sci. China Chem. 532118 
[2] Kristina Konstas, Theresa Osl, Yunxia Yang, Michael Batten, Nick Burke, Anita J Hill et al 2012 J. Mater. Chem. 2216698

[3] Mueller U, Schubert M, Teich F, Puetter H, Schierle-Arndt K and Pastre J 2006 J. Mater. Chem. 16626

[4] Demin Liu, Kuangda Lu, Christopher Poon and Wenbin Lin 2013 Inorg. Chem. doi:10.1021/ic402194c

[5] Pilkington M, Gross M, Franz P, Biner M, Decurtins S, Stoeckli-Evans H et al 2001 J. Solid State Chem. 159262

[6] Chandan D, Tanay K, Bishnu P B, Arijit M and Rahul B 2014 Acta Crystallogr. B 703

[7] Paul M F, Andrea R B, Carine L, Gérard F and Anthony K C 2004 Chem. Commun. 4368

[8] Yaghi O M, Guangming L and Groy T L 1995 J. Solid State Chem. 117256
[9] Siau Gek Ang, Bai Wang Sun and Song Gao 2004 Inorg. Chem. Commun. 7795

[10] Ayhan Elmali 2000 Turk. J. Phys. 24667

[11] Seguatni A, Fakhfakh M, Smiri L S, Gressier P, Boucher F and Jouini N 2012 J. Solid State Chem. 1877

[12] Binitha M P and Pradyumnan P P 2013 Phys. Scr. 87 065603

[13] Manhas B S, Kalia S B, Sardana A K and Lumban K 2007 Indian J. Chem. Sect. A 46A 1226

[14] Anderson P W 1950 Phys. Rev. 792

[15] Kai-Silke B, Phalguni C and Karl W 1996 Inorg. Chem. 35 2704

[16] Fernando S D, Catalina R-P, Joaquín S, Francesc L and Miguel J 2006 CrystEngComm. 8530 